\title{
Social career management: social media and employability skills gap.
}

\begin{abstract}
Social capital theorists have established decades ago that well connected people do better in life. The emergence of online social networking sites has given a new impetus to building and exploiting networking for career management. While professionals acknowledge that social networking is essential for business and development, research indicates that new graduates coming into the corporate world are not equipped with the up to date skill set. Through the lens of improved employability objectives, this paper draws conclusions from a recent study of UK business graduates and their use of social networking. The paper presents for discussion an employability skill set for contemporary business professionals based on the literature, and calls for higher education to address the skill gap shown by our study.
\end{abstract}

Keywords: educational technology, employability, knowledge management, higher education, student lifecycle.

Highlights: We examine the patterns of social networking usages for business and socialising and their implications for career management. The research involved a quantitative study of 190 business graduates. Membership in professional social networking sites does not automatically imply better job options for undergraduates. Postgraduate students join business networks out of curiosity and exploration of new opportunities, not through peer-pressure. Usage for job seeking is low. We argue that a new employability agenda for universities should include social networking skills.

\section{Introduction}

Online social networking (SN) applications have become a part of daily life for many. The popularity of social media has seen an unprecedented rise over the past decade: LinkedIn dominates the professional social networking sector with over 150 million registered members (LinkedIn About Us, 2012) with 21\% aged between 18 and 21 years old (Socialnomics, 2011). Facebook is reportedly one of the top visited websites 
(Alexa Internet Inc., 2011), attracting over half a billion users world-wide (Gonzalez, 2011). Twitter rapidly gained worldwide social networking and microblogging recognition with over 500 million users (Twitter, 2012). Enthusiasm for social media is yet to reach its plateau, as the most recent addition to the social media scene, Google+ showed the most rapid member gain to 101,978 in less than a year after its launch (Socialstatistics, 2012). Whether updating status on Facebook, tweeting the latest news or joining a professional community on LinkedIn, social networking has earned its place in our everyday life for both leisure and business.

Extant literature (Richardson \& Hessey, 2009) suggests that social networking has changed the way individuals communicate and associate with one another. Some research attention has been focused on how social media use is associated with social capital (e.g. Steinfield, Ellison \& Lampe, 2008). Individual characteristics of social network members have been shown to determine the different benefits its users draw from social media by (Ryan \& Xenos, 2011). They argue that lonely and unsociable individuals tend to spend more time on social media and passively exploit associations and social capital, while users with higher leadership scores tend to provide more active social contributions and use the network for self-promotion. Recent studies focus on various dimensions of online social networks and their use in the student lifecycle, e.g. knowledge management, social capital and career management skills (e.g. Benson, Morgan, \& Filippaios, 2010). Despite the potential impact of social media on trends in professional networking, social recruitment and development of relevant employability skills, there is a distinct lack of empirically derived theory in this area. Arguably Facebook is a relatively recent social phenomenon and according to Ryan and Xenos, (2011) there have been limited opportunities for exploratory research. Despite the salience of a lack of professional networking skills, very little empirical research explores the relationships between social media uses and social career management, or the SN employability skill set required for current graduates that may enhance their career prospects, including the entrepreneurship opportunities offered by social media.

This study provides an insight into the changing landscape of social connections on social media in order to understand: (1) how professionals build and exploit social capital on business and leisure social networks, and (2) the extent to which future graduates need to build awareness of the social media opportunities in career management and entrepreneurship. This research addresses calls in the literature to investigate the relationship between networking and career success (Bozinelos, 2003) in the social media context, and provides insights into ways higher education may better equip its students with current employability skills. By identifying patterns of social media uses for business and leisure, this research aims to promote career management skills that may help graduates make better use of social networking connections, to build their social capital and enhance their employability prospects. In doing so, this paper extends the theoretical understanding of individual social media usage, and challenges commonly held beliefs about high delineation between leisure and professional social networking.

From a quantitative study of 190 postgraduate and undergraduate students from a UK Business School, this article provides an insight on intuitive, rather than informed use of social networks by Business students to improve their employability.

While the study is part of wider research into the use of social networks by business students and graduates, data collected in 2012 have revealed an interesting insight into the way younger social networking users view opportunities of knowledge management through social media, build social capital via connections with 
Business School alumni and professionals, and establish their online professional presence through business networking sites. This article opens discussion into the changes of the employability skill set required for current and future Business graduates in light of the increasing role of social media in business relations. The rest of the article is structured as follows. The notion of social capital is central to online social networking research; section 1.1 discusses the extant literature on social capital theory in relation to online SN. The novel nature of social relationships online, discussed on section 1.2, has implications for individual skills and competencies, covered in section 1.3, along with discussion of how successful professional networking can improve business and employability prospects. Section 2 describes the research instrument, and opens the discussion of the quantitative study of UK business graduates and trends in their use of social networking sites for business and leisure. Section 3 draws out recommendations on the new networking skill set for higher education to address, with the view of improving graduate employability in the era of the digital economy. Section 4 draws conclusions from the study and sets out the agenda for the place of social connections in graduate careers, whilst outlining future research directions.

\subsection{Social Connections: Knowledge and Social Capital Repository}

Social networks seamlessly enable existing relations and facilitate building new ones in leisure and professional domains alike. In his seminal work Coleman (1990) associates social capital not with 'a single entity, but a variety of different entities, with two elements in common: they all consist in some aspect of social structures, and they facilitate certain actions of actors within the structure' (p.98). Relationships or ties, as they are popularized in the literature, play a significant role in the academic interpretation of social capital. Strong ties are characteristic of family or friendship bonds, while weak ties represent relationships in formal networks, such as organizations and communities. Being formed by individuals from heterogeneous backgrounds and intentions are characteristic of the networks linked by weak ties. Interestingly enough, the notion of social capital is often linked to 'structural components' or nodes in social networks. Extant literature (Brehm \& Rahn, 1997) distinguishes social capital entwined in strong ties of a network as bonding social capital, while the weak ties yield a network with bridging and linking social capital. As Granovetter (1973) points out in his seminal work, 'Whatever is to be diffused can reach a larger number of people, and travel greater social distance ... when passed through weak ties rather than strong' (p. 1366). In this article the social capital metaphor is viewed through the lens of what assets can be 'reached' and what resources can be 'passed' through the weak ties network.

Putnam (1995) refers to social capital as characteristic 'social life-networks' which enable members of the network to achieve collective objectives. For Putnam shared norms and trust facilitate cooperative goal attainment. From the perspective of the individual actor, Bourdieu articulates the characteristics of the social capital in terms of size and quality of the network. While the overall quality of the existing network in which an individual is a member also counts, the benefits are drawn from the number of connections a node can 'effectively mobilize' in order to achieve a goal (Bourdieu, 1986). In Bourdieu's view actors are seen as individual nodes striving to improve their positions by drawing upon their social capital within the larger social environment. 


\subsection{Social network resources and career success}

The notion of career success occupies an important place in social capital theory. In line with Loury, (1977); and Coleman, (1990) mentoring, job partnering, and mutual support have been advocated to have a positive connection to success in education. Relationships in social networks, including professional ties, constitute an important facet of social capital (Bozionelos, 2003; Seibert, Kraimer, \& Liden, 2001). While social capital is seen as the outcome or product of connections between nodes in a network, access to a wealth of resources is what makes a relationship significant to an individual. These assets are even more valuable the more extensive the network and stronger the ties. These resources comprise job or professional information, power influence, professional solidarity (Adler \& Kwon, 2002; Coleman, 1990), which would not be accessible to an individual who is not a member of the social network. Earlier research (Lin, 1999) shows the contribution of social capital to career success through priority access to information on a job opening which an individual can obtain through connections, or other nodes in a network can favorably influence a promotion decision.

The density of the social network of connections is another determinant of career success (Bozionelos, 2003; Seibert, Kraimer \& Liden, 2001). Research assessing differences in the outcomes of different elements of social capital, such as mentoring relationships and network resources indicate that in western societies, network resources have an impact beyond mentoring on both extrinsic (promotions, salary increases) and intrinsic (job satisfaction, respect) elements of career success (Bozionelos, 2003). However cultural differences have been found (Wang \& Bozionelos, 2007) and must be taken into consideration, particularly in Eastern organisations. Network resources have also been categorized into instrumental (functions to advance career interests through for example access to senior managers, influencing decisions on assignments) and expressive (offering socioemotional support such as friendship). It is not yet clear whether these distinctions remain with online social networks.

\subsection{The changing nature of employability skills}

The literature indicates (Archer \& Davison, 2008) that employers of new graduates increasingly consider social skills (particularly communication and team working) and personality as more important than the degree qualification. Key hard skills include literacy and numeracy, with satisfaction in these areas low. Satisfaction rates for commercial awareness, communication, literacy, analysis and decision-making skills, 'passion' and relevant work experience are very low. An Institute of Directors report (Graduate Employability Skills, 2007) also emphasised work ethic as important, including being hard working, reliable, able to meet deadlines, and punctual. Although some of these aspects such as personality and work-ethic are likely to come with maturity (and could be viewed as hard to modify), there are things that can be built-in to the University learning experience that can encourage the required behaviours (and related personality 'traits'). ICT and social media skills are viewed as increasingly important, particularly in marketing related work, with employers expecting graduates to be well-versed in the use of online social media. At the same time some employers use social media to check behaviour patterns of potential graduates, and one could argue that students need to be made more aware of this. 


\section{Method}

This study is a part of a wider research into the use of social networks by students and professionals, originally piloted with European and UK business graduates in 2010. Results of the earlier study on social networking usage uncovered different ways in which students realise the benefits of social media connections. Use of online social networking for career management was virtually unknown to undergraduate UK students, while postgraduate students and international graduates reveal a higher level of exploitation of social capital through social media (see Benson, Morgan, \& Filippaios, 2010). It was therefore of interest to investigate whether the perceptions of UK business graduates about professional usage of social networks have changed over time.

Results of the quantitative study conducted in 2012, reported in this paper, help shed some light onto the way business graduates at a UK university view opportunities of knowledge management through social media, build social capital via connections with business school alumni and professionals, and establish their online professional presence through business networking sites.

\subsection{Sample description and statistics}

Paper-based questionnaires were distributed to a targeted population of UK business students. We chose not to use social media itself as we wished to capture any non-users as well as regular users. Both undergraduate and postgraduate students participated and the total distribution of the 190 usable questionnaires is shown in table 1 . Although our sample contains a significant proportion of undergraduate students the overall distribution is not significantly different from the distribution of the student population in the UK Higher Education sector.

Table 1. Undergraduate and Postgraduate Questionnaire Numbers

\begin{tabular}{cccc}
\hline & Undergraduate & Postgraduate & Total \\
\hline Count of Questionnaires & 168.00 & 22.00 & 190.00 \\
\hline
\end{tabular}

Questionnaires cover a wide student population with approximately 30\% male participants and 70\% female participants. As it can be seen from table 2 the average age of the student population was 22.11 years with a significant difference between undergraduates (21.50 years) and postgraduate (26.62 years). Female postgraduate students were the oldest participants with male undergraduate being the youngest.

Table 2. Average age by degree type and gender

\begin{tabular}{lccc}
\hline & Undergraduate & Postgraduate & Total \\
\hline Male & 21.21 & 25.70 & 22.06 \\
Female & 21.61 & 27.45 & 22.14 \\
Total & $\mathbf{2 1 . 5 0}$ & $\mathbf{2 6 . 6 2}$ & $\mathbf{2 2 . 1 1}$ \\
\hline
\end{tabular}


The average work experience of our participants showed differences between groups (see table 3), with parttime postgraduate students having on average 13 years of work experience. This is significantly different from the total sample which exhibited an average work experience of 3.33 years. It is therefore expected that postgraduate students will be far more focused on career development than the undergraduate students.

Table 3. Average work experience by degree type and mode of study

\begin{tabular}{lccc}
\hline & Undergraduate & Postgraduate & Total \\
\hline Part-time & & 13.00 & 13.00 \\
Full-time & 3.11 & 3.25 & 3.12 \\
Total & $\mathbf{3 . 1 1}$ & $\mathbf{5 . 2 0}$ & $\mathbf{3 . 3 3}$ \\
\hline
\end{tabular}

In our first question we asked participants to answer when they first joined Facebook, LinkedIn or any other social network, rank the networks from the most used to the least used, and also provide us with an average approximation of their usage per week. Although average use approximations may be error prone, the results are not out of line with other studies (e.g. Wang, 2013), furthermore here we are comparing primarily each individual's use of two networks, allowing valid comparison. For the 'other' network we received 47 answers with 40 of them indicating Twitter as the selected SN. Table 4 presents the data for joining date, use rankings and average usage per week. Facebook appears to be the network that students joined first with the average year being 2008. Students do not join LinkedIn until 3 years later with average year 2011. Facebook ranks first in terms of use for undergraduates with 'other' network second and LinkedIn third. The order changes for postgraduate students who put LinkedIn in second place. The pattern of average use is also interesting, as Facebook comes first with an average use of more than 8 hours per week and almost equal use between undergraduates and postgraduates. A t-test of difference between their uses does not reveal any statistical difference. The picture is different for LinkedIn where postgraduate students are much heavier users than undergraduates with almost 4 times longer spent on LinkedIn. A difference is observed in the average use of other social networks but it is not statistically significant.

Table 4. Statistics of social network use

\begin{tabular}{lccc}
\hline Values & Undergraduate & Postgraduate & T-test \\
\hline Facebook (Joining date) & 2008 & 2008 \\
\hline Ranking & 1.26 & 1.44 & -0.17 \\
\hline Average Use (hrs per week) & 8.43 & 8.88 & 2011 \\
\hline LinkedIn (Joining Date) & 2011 & 2.00 & $-2.26^{* *}$ \\
\hline Ranking & 2.47 & 4.39 & 2009 \\
\hline Average Use (hrs per week) & 1.13 & 2.60 \\
\hline Other (joining date) & 2010 & 1.87 & \\
\hline Ranking & \\
\hline
\end{tabular}




$\begin{aligned} & \text { Average Use (hrs per week) } \\ & \text { A** statistically significant at 1\%, } * * \text { statistically significant at } 5 \%, * \text { statistically significant at } 10 \%, \text { +statistically significant }\end{aligned}$
at $15 \%$

One key issue under investigation in this study was to explore the motivation of students when joining a social network and whether this is related to social elements or career prospects. We have asked students to express whether they agree or disagree with certain statements when referring to a specific network. Table 5 presents the data comparing undergraduate students and postgraduate students for Facebook. Keeping in touch with friends was the statement that attracted significant agreement whilst finding business was the one with the least agreement. This verifies the nature of Facebook as primarily a social network for entertainment and not for business networking. Interesting is the fact that in the vast majority of categories the views of undergraduate and postgraduate students are not statistically different. The only exception comes to the answer about the use of Facebook for making new friends. Postgraduate students showed a much stronger disagreement with this statement than undergraduate students.

Table 5. Main motivation behind joining Facebook (1 - Strongly Agree, 2 - Agree, 3 - Neither Agree nor Disagree, 4 Disagree, 5 - Strongly Disagree)

\begin{tabular}{lccc}
\hline Facebook & UG & PG & T-test \\
\hline To be generally sociable & 2.19 & 2.15 & 0.15 \\
\hline Peer pressure (old friends) & 3.20 & 3.00 & 0.61 \\
\hline Peer pressure (new friends) & 3.32 & 3.41 & -0.30 \\
\hline Find a job & 4.07 & 4.43 & -1.17 \\
Find business & 4.03 & 4.24 & -0.69 \\
Curiosity & 2.72 & 2.43 & 1.05 \\
\hline Keeping in touch with friends & 1.74 & 1.64 & 0.39 \\
Making contact with people from University & 2.24 & 2.24 & 0.02 \\
\hline Making new friends & 2.96 & 3.62 & $-1.99 * *$ \\
\hline *** statistically significant at 1\%, ** statistically significant at 5\%, * statistically significant at 10\%, +statistically significant \\
at 15\%
\end{tabular}

The second network under investigation was LinkedIn and the relevant answers are presented in table 6. Generally the answers for LinkedIn are closer to the disagreement side when compared to those given for Facebook. Peer pressure from either old or new friends seems to be the least important factor for joining LinkedIn. This contradicts the idea of creation and sustainability of social capital through the social network. It appears that curiosity is the most important factor for postgraduate students followed by finding a job. Finding a 
job followed by finding business are the two most important factors for undergraduates. Similarly to Facebook, the results between undergraduates and postgraduates for these items do not differ statistically. A marginal difference can be found for 'curiosity' with postgraduate students considering it a key factor, along with making new friends. The latter motivation is significantly different between the two groups with postgraduate students showing a strong disagreement whilst undergraduates showing a more neutral approach. It is evident here that postgraduate students are strongly aware that LinkedIn is a professional social network and should not be used to make friends.

Table 6. Main motivation behind joining LinkedIn (1 - Strongly Agree, 2 - Agree, 3 - Neither Agree nor Disagree, 4 - Disagree, 5 - Strongly Disagree)

\begin{tabular}{|c|c|c|c|}
\hline LinkedIn & UG & PG & T-test \\
\hline To be generally sociable & 3.11 & 3.14 & -0.05 \\
\hline Peer pressure (old friends) & 3.82 & 3.80 & 0.04 \\
\hline Peer pressure (new friends) & 3.50 & 3.90 & -0.76 \\
\hline Find a job & 2.00 & 2.18 & -0.36 \\
\hline Find business & 2.36 & 2.60 & -0.41 \\
\hline Curiosity & 2.50 & 1.91 & $1.52+$ \\
\hline Keeping in touch with friends & 3.32 & 3.70 & -0.74 \\
\hline Making contact with people from University & 2.86 & 2.89 & -0.05 \\
\hline Making new friends & 2.95 & 4.22 & $-2.47 * *$ \\
\hline
\end{tabular}

To compare the motivations of undergraduates and postgraduates for each of the two networks the answers for undergraduate and postgraduate students and the relevant t-test statistic are shown in Table 7. Results show an interesting picture. Both groups differentiate between the two networks regarding motives like finding a job or finding business. This indicates that over the last couple of years and since our original study undergraduate students have increased their awareness on the different use of the two networks. Undergraduate students differentiate the two networks by an additional three motives. It appears that there is significant difference regarding the motive of joining a network to be generally sociable as undergraduates clearly distinguish between the two networks. Also interesting, with respect to social capital development, is the fact that peer pressure from old friends is less a motive for LinkedIn than for Facebook. 
The final dimension that we wish to explore is whether there is any change in behaviour in the use of social networks between the first time that people joined and their consequent use. To this respect we would like to investigate whether when students first join a network they spend significantly more or less time than their use in consequent periods. As average use estimates can be over reported (see Junco, 2013), we asked a range of questions regarding frequency of activities such as updating profiles or taking part in discussion boards.

Table 8 presents the data for the frequency of visiting the preferred social network, the activity in discussions and thus exchange of information and ideas, and the frequency of updating the profile. A clear distinction exists between undergraduates and postgraduates in the frequency of logging in. Postgraduates are more frequent users and the majority are logging in more than 2-3 times a day.

On the other hand this is contradicted by the updating of profiles. Postgraduates update their profile on average on a monthly basis but undergraduates, although they are logging in less frequently, update their profile almost on a weekly basis. For undergraduates active engagement and sharing of information is more important than simply logging in a social network.

Table 7. Comparison of Facebook and LinkedIn for undergraduate and postgraduate students (1 Strongly Agree, 2 - Agree, 3 - Neither Agree nor Disagree, 4 - Disagree, 5 - Strongly Disagree)

\begin{tabular}{|c|c|c|c|c|c|c|}
\hline & \multicolumn{3}{|c|}{ Undergraduate } & \multicolumn{3}{|c|}{ Postgraduate } \\
\hline & Facebook & LinkedIn & T-test & Facebook & LinkedIn & T-Test \\
\hline To be generally sociable & 2.19 & 3.11 & $-3.18 * * *$ & 2.15 & 3.14 & -1.58 \\
\hline Peer pressure (old friends) & 3.20 & 3.82 & $-1.87 * *$ & 3.00 & 3.80 & -1.57 \\
\hline Peer pressure (new friends) & 3.32 & 3.50 & -0.59 & 3.41 & 3.90 & -1.06 \\
\hline Find a job & 4.07 & 2.00 & $6.76^{* * *}$ & 4.43 & 2.18 & $4.83 * * *$ \\
\hline Find business & 4.03 & 2.36 & $5.56 * * *$ & 4.24 & 2.60 & $3.18 * * *$ \\
\hline Curiosity & 2.72 & 2.50 & 0.83 & 2.43 & 1.91 & 1.15 \\
\hline $\begin{array}{l}\text { Keeping in touch with } \\
\text { friends }\end{array}$ & 1.74 & 3.32 & $-5.99 * * *$ & 1.64 & 3.70 & $-4.31 * * *$ \\
\hline $\begin{array}{l}\text { Making contact with people } \\
\text { from University }\end{array}$ & 2.24 & 2.86 & $-2.21 * *$ & 2.24 & 2.89 & -1.13 \\
\hline Making new friends & 2.96 & 2.95 & 0.02 & 3.62 & 4.22 & -1.17 \\
\hline
\end{tabular}

*** statistically significant at $1 \%, * *$ statistically significant at $5 \%, *$ statistically significant at $10 \%,+$ statistically significant at $15 \%$

Table 8. Use of preferred network at initial period of registration (Frequency, 1 - 2-3times a day, 2 - daily, 3 - weekly, 4 - monthly, 5 - hardly ever, 6 - never) (Activity in discussions, 1 - always, 2 - sometimes, 3 rarely, 4 - never) (Frequency of updates, 1 - daily, 2 - weekly, 3 - monthly, 4 - less often)

\begin{tabular}{cccc}
\hline & Undergraduates & Postgraduates & T-test \\
\hline Frequency of Logging in & 2.07 & 1.68 & $1.66^{* *}$ \\
\hline
\end{tabular}




\begin{tabular}{llcc}
\hline Activity in Discussions & 2.45 & 2.27 & 0.91 \\
Update of profile & 2.57 & 3.00 & $-1.87 * *$ \\
\hline$* * *$ statistically significant at $1 \%, * *$ statistically significant at $5 \%, *$ statistically significant at $10 \%,+$ statistically significant \\
at $15 \%$
\end{tabular}

Although the use of a social network in the first instance might be quite intensive we wanted to explore whether this was followed by a consistent use of the preferred network for social or business purposes. Table 9 presents the relevant information for social use and table 10 for business use. Results show that the behaviour of undergraduates and postgraduates is very similar. Both groups use their preferred social network more or less about the same as when they first engaged with it.

The frequency of logging in has fallen for postgraduates and remained stable for undergraduates. There was no significant change in behaviour when engaging in discussions. The results indicate that there is consistency in use of social networks for socialising and even when time passes there still something to be gained from using them, they are not a passing fad but have become a part of their social life.

Table 9. Use of preferred network for Socialising (Use, 1 - More, 2 - About the same, 3 - less, 4 - Not at all) (Frequency, 1 - 2-3 times a day, 2 - daily, 3 - weekly, 4 - monthly, 5 - hardly ever, 6 - never) (Activity in discussions, 1 - always, 2 - sometimes, 3 - rarely, 4 - never) (Frequency of updates, 1 - daily, 2 - weekly, 3 monthly, 4 - less often)

\begin{tabular}{lccc}
\hline & Undergraduate & Postgraduate & T-test \\
\hline Use for Socialising & 1.99 & 2.13 & 0.24 \\
\hline Frequency of Logging in & 1.95 & 2.23 & -1.17 \\
Activity in Discussions & 2.48 & 2.59 & -0.57 \\
Update of profile & 2.79 & 3.06 & -0.48 \\
Average use (hrs per week) & 9.60 & 7.28 & 0.35 \\
\hline *** statistically significant at 1\%, ** statistically significant at 5\%, * statistically significant at 10\%, +statistically significant \\
at 15\%
\end{tabular}

Results for Business Networking, presented in table 10, indicate an interesting difference between undergraduates and postgraduates. Undergraduates suggest that after a while they hardly use their preferred network for business networking. Although postgraduates also use it less when compared to first use, their answer is statistically different to the undergraduates. It appears that postgraduate students see more benefits from utilising social networks for business networking purposes and in that sense the results confirm our findings in previous studies.

Table 10. Use of preferred network for Business Networking (Use, 1 - More, 2 - About the same, 3 - less, 4 - Not at all) (Frequency, 1 - 2-3times a day, 2 - daily, 3 - weekly, 4 - monthly, 5 - hardly ever, 6 - never) (Activity in discussions, 1 - always, 2 - sometimes, 3 - rarely, 4 - never) (Frequency of updates, 1 - daily, 2 weekly, 3 - monthly, 4 - less often)

\begin{tabular}{llll}
\hline & Undergraduate & Postgraduate & T-test \\
\hline
\end{tabular}




\begin{tabular}{|lccc|}
\hline Use for Business Networking & 3.42 & 2.86 & $1.94 * *$ \\
\hline Frequency of Logging in & 3.81 & 3.56 & 0.51 \\
\hline Activity in Discussions & 3.12 & 3.26 & -0.62 \\
\hline Update of profile & 3.02 & 3.17 & -0.46 \\
\hline Average use (hrs per week) & 9.51 & 4.33 & 0.48 \\
\hline ****
\end{tabular}

*** statistically significant at $1 \%, * *$ statistically significant at $5 \%, *$ statistically significant at $10 \%,+$ statistically significant at $15 \%$

Our last section of results relates to the use of alternative social networking media. Although the dominance of Facebook and LinkedIn as the main players cannot be challenged, a number of alternative media have emerged and attracted attention.

Table 11. Use of alternative social networks (1- Used a little, 2 - Used a lot)

\begin{tabular}{lccc}
\hline & Undergraduates & Postgraduates & T-test \\
\hline Blogs & 1.10 & 1.20 & -0.99 \\
Twitter & 1.40 & 1.09 & $2.03^{* *}$ \\
Wikipedia & 1.58 & 1.67 & -0.76 \\
YouTube & 1.82 & 1.81 & 0.11 \\
\hline
\end{tabular}

*** statistically significant at $1 \%, * *$ statistically significant at $5 \%, *$ statistically significant at $10 \%,+$ statistically significant at $15 \%$

Blogs, Twitter, Wikipedia and You tube are useful sources of information and possibly exchange of information. Although their use can be quite diverse we want to explore through data presented at table 11 whether students use them a lot or little. For undergraduates the most frequently used SN is YouTube whilst the least used SN is blogs. Similarly for postgraduates YouTube is the most popular, with Twitter the least popular. The use of Twitter is the only option that also gives us a statistical significant difference between postgraduates and undergraduates, with more undergraduates saying they used this 'a lot'. This finding together with the fact that Twitter was the most popular network under the 'other' category in our first question highlights the need for further research in the area of changing social networks and gives an indication of how quickly new networks can change usage.

\section{Discussion: Place of Social Connections}

The idea that social capital, including interpersonal relationships, assets embedded in relationships and processes, contribute to career success has surfaced in multiple studies of social capital theory (Adler \& Kwon,2002; Coleman, 1990; Seibert, Kraimer \& Liden, 2001). However, in recent years this view has gained influence (Bozionelos, 2003; Lin,1999) as a networking approach to study of career success. While in the past there appeared to be a clear separation of social network memberships for professional purposes and leisure activities, the line is recently starting to blur and differences in their usage patterns are starting to emerge. According to the results of our 2012 study both postgraduate and undergraduate students are highly engaged 
with Facebook with an average use of over 8 hours per week. However, undergraduate students are mostly engaged with Facebook, while professional networks are least popular. Postgraduate students choose LinkedIn as their second choice for SNS, however their actual use of professional SNS such as LinkedIn is significantly higher than undergraduates.

Online social networking seamlessly enables real-life relationships through information technology (Calabrese \& Borchert, 1996), facilitating the building of new relationships, maintaining existing ones and exploiting online social capital to its full extent. According to the results of our study, peer pressure from friends appears to be the least influencing factor for joining a professional network, when compared to a leisure network such as Facebook. Clearly postgraduate students are strongly aware that LinkedIn is a professional social network and is unlikely be used to make informal friends. It is evident that postgraduate students join professional networks to search for and explore new opportunities, building social capital, while undergraduate students think they may simply find a job. This reveals a shift compared to our original 2010 study, as undergraduate students have increased their awareness of the different uses of the two types of social networks, however still demonstrates a naivity in the use of professional networks.

Differences in the way undergraduate and postgraduate students use professional SNS have been revealed. While postgraduate students update their profiles on average once a month, undergraduates are more likely to make frequent, even weekly, changes to their profiles. They are also likely to have a higher frequency of logging in. Active engagement and sharing of information rather than simple logging in a social network tends to be important for undergraduates. Also, the fact that Twitter is least popular amongst postgraduates can be explained by the need for interaction frequency. Data on professional networking usage by undergraduates reveal that after the introductory period they do not use their preferred network for business. This is likely to be because they either set unrealistic expectations of finding a job by simply registering on the right social network or are unaware of how to use business networking sites.

\subsection{Recommendations: New skill set required?}

One key recommendation from these initial findings would be to include more information to students during their studies regarding the various uses of online social networking and include high level skills in $\mathrm{SN}$ as a learning outcome. The impact of student online networking on intrinsic and extrinsic career success should be discussed, although further research will be needed in this area. As employers increasingly demand ICT and SN skills for a wide range of jobs, ensuring that students are fully aware of and skilled in the various uses of such networks will be important.

\subsection{Employability needs of students at each level of study}

It has become increasingly important to explicitly embed employability needs into the curriculum, and develop such skills across each level (year of study). Our research suggests that despite students' prolific use of SNS, they do need education regarding effective engagement with SNS. Below is a brief outline of some of the key employability skills and SNS skills that may be relevant for each year. 
$\mathbf{1}^{\text {st }}$ Year UG - whilst learning about employability skills such as CV writing and presentation skills should also learn how to create a positive online profile and gain understanding of how employers use SNS to assess job applicants. They should also be made aware of privacy and security issues, along with email and online comment etiquette.

$\mathbf{2}^{\text {nd }}$ Year UG - alongside learning networking and negotiating skills, students should gain understanding of how to assess and update profiles and the use of SNS in employment related networking. They also would benefit from an awareness of the concept of online social capital and use of this for internships, placements and volunteering.

Final Year UG - students could benefit from a much deeper understanding of how to research organizations and job roles online, and a critical analysis of SNS information to aid job search.

PG students - require a deeper understanding of all of the above along with how to make best use of Masters level study in an online environment and critically analyse information and their own online social capital.

The SNS elements will need to be delivered in interesting, even inventive ways because many students already believe they have a good understanding of the use of social networks. Research supports our view that this is not the case and therefore students must be made aware of the way employers use SNS and the full use of social capital through SNS.

\section{Conclusions}

Online networking has been positively linked to building and reinforcing social capital. In turn better connected people are thought to enjoy an advantage in career management.

Besides simple socialising thus, online social networks have an impact on business relations. Analysis of data on the use of SN from business undergraduate and postgraduate students provided an empirical lens on their online behaviour. Further research is needed to assess, for example, links between actual usage, belonging to professional groups, work experience, and the skills required to build job related skills and develop online capital.

Undergraduate students primarily use SN for social purposes whilst postgraduates focus primarily on the business use of SNS. It has become evident that social networking awareness is missing in the Higher Education curriculum. Despite the fast moving uptake of technology and younger people's tendency to take social networking for granted, our study suggests their knowledge (or lack of) regarding good use of SNS has not increased during the two years of our study. It is important to address these issues through further research studies into social media and its business applications.

\section{References}

Adler, P.S. ,Kwon, S.-W. (2002): 'Social Capital: Prospects for a New Concept’, Academy of Management Review, 27,1740. 
Archer, W. , Davison, J. (2008) Graduate Employability: What do employers think and want. CIHE (Council for Industry \& Higher Education)

Benson, V., Filippaios, F., Morgan, S (2010) Online social networks: changing the face of business education and career planning. International J. of eBusiness Management, 4(1), pp. 20-33.

Brehm, J., Rahn, W. (1997): Individual-Level evidence for the causes and consequences of Social Capital. American Journal of Political Science 41, 3, 999-1023.

Bourdieu, P., ( 1986): The forms of capital, in: Richardson, J.G. (Ed.), Handbook of Theory and Research for the Sociology of Education. Greenwood Press, New York, pp. 241-258

Bozionelos, N. (2003): 'Intra-Organizational Network Resources: Relation to Career Success and Personality', International Journal of Organizational Analysis, 11: 41-66.

Calabrese, A., Borchert, M. (1996): Prospects for electronic democracy in the United States: Rethinking communications and social policy. Media, Culture, and Society 18: 249-268.

Coleman, J., (1990): Foundations of Social Theory. Harvard University Press, Cambridge, MA.

Ellison, N. B., Steinfield, C., \& Lampe, C. (2007). The benefits of Facebook “'friends:' Social capital and college students' use of online social network sites. Journal of Computer-Mediated Communication, 12, 1143-1168. doi:10.1111/j.10836101.2007.00367.x.

Fukuyama, F. (1995): Trust: The social virtues and the creation of prosperity. NY: Free Press.

Graduate Employability Skills. (2007) Institute of Directors Skills Briefing.

Granovetter, M.S.(1973): The Strength of Weak Ties. The American Journal of Sociology 78, 6, 1360-1380

Junco, R. (2013): Comparing actual and self-reported measures of Facebook use. Computers in Human Behavior.

Volume 29, Issue 3, 626-631

Lin, N. (1999): 'Social Networks and Status Attainment', Annual Review of Sociology, 25:,467-87.

LinkedIn - About Us". Press.linkedin.com. http://press.linkedin.com/about. Retrieved April 12, 2012.

Loury, G. (1977): A dynamic theory of racial income differences. Pp. 153-186 in P.A. Wallace and A. Le Mund, eds., Women, minorities, and employment discrimination. Lexington, MA: Lexington Books.

Putnam, R.D. (1995): Bowling Alone: America's Declining Social Capital. Journal of Democracy 6,1, 65-78. 
Seibert, S.E., Kraimer, M.L. and Liden, R.C. (2001): 'A Social Capital Theory of Career Success' Academy of Management Journal, 44: 219-37.

Ryan, T. \& Xenos, S., (2011) Who uses Facebook? An investigation into the relationship between the Big Five, shyness, narcissism, loneliness, and Facebook usage. Computers in Human Behavior. 27, 1658-1664 doi: 10.1016/j.chb.2011.02.004

Socialnomics (2011) 100 Million on LinkedIn $\quad-$ Infographic by Country available at: http://www.socialnomics.net/2011/03/28/linkedin-hits-100-million-breakdown-by-country-graphic/ Erik Qualman | March 28, 2011

Socialstatistics (2012) Google+ Statistics. Available at: http://socialstatistics.com/ Accessed on 23/07/2012

Steinfield, C., Ellison, N. B., \& Lampe, C. (2008). Social capital, self-esteem, and use of online social network sites: A longitudinal analysis. Journal of Applied Developmental Psychology, 29, 434-445. doi:10.1016/j.appdev.2008.07.002.

Twitter.com Site Info. Alexa Internet. http://www.alexa.com/siteinfo/twitter.com. Retrieved 2012-07-02.

Wang, L., Bozionelos, N. (2007): An investigation on the attitudes of Chinese workers towards individually-based performance related reward systems. International J. of Human Resource Management 18, 284-302.

Wang, X. (2013): Applying the integrative model of behavioural prediction and attitude functions in the context of social media use while viewing mediated sports. Computers in Human Behavior 29, 1538-1545. 